\title{
Different Ways of Teaching Digital Communication
}

\author{
Sen Xiang, Jin $\mathrm{Wu}^{*}$, Xiujuan Zheng, Huiping Deng, and Jin Liu \\ College of Information Science and Engineering, Wuhan University of Science and Technology, \\ Wuhan Hubei 430081, China
}

\begin{abstract}
Digital communication is a major course for electronics and information engineering students. The course is complex in theory, closely related with practical communication systems, and its prior courses are difficult. All these factors introduce difficulties and challenges to the teaching activity. In order to improve the teaching quality of the course, we make attempts in six aspects, e.g. reforming the knowledge system based on information flow of communication systems, reorganizing teaching content, online and offline teaching, combination of theories and hardware systems, experiments and finally a comprehensive grading system. These teaching research issues bring benefits to the students, not only in the theory but also the skills in dealing with the practical communication systems. In such a manner, the students will be well-cultivated to be qualified engineering talents with solid theory and strong practical ability.
\end{abstract}

\section{Introduction}

With the booming development in economy and technological fields, digital communication technologies such as the well-know 5G [1], have become a new type of basic infrastructure that push towards the development of our economies and emerging high techniques in the future. In this new era of digital communication, colleges and universities have the task of cultivating students and training talents, and it is of great importance to provide high-quality engineering talents who are solid in theory and strong in practice and innovation [2].

The course of "digital communication" is quite difficult and faces the following challenges. First of all, the course needs solid theoretical foundation. To be specific, it is based on matrix theory, probability theory and other mathematical theories, where complex and abstract mathematical derivations are involved, making it difficult for students to learn. Secondly, the course requires a large number of prior courses such as digital circuits, signals and systems, digital signal processing, and communication principles. In the class, it is often needed to recall the contents of these prior courses. Finally, the course is closely related to the practical application of software and hardware systems such as mobile phones. Nevertheless, the theoretical content in the textbook is quite abstract and different with the

\footnotetext{
* Corresponding author: wujin@wust.edu.cn
} 
communication devices. The above problems reduce the effectiveness of teaching and cannot meet the skill needed for students when they are employed.

Several attempts have been made by the researchers on similar courses. Silage [3] coupled the traditional analytical approach with the simulation of the system for further design, analysis, insight and motivation. Mahmood [4] took a deep inside of Software Project Management and Software Quality Assurance, where the authors underlined the students' perspective, highlighted the inherent issues and suggested ways to improve the delivery of students. Ghassemlooy [5] proposed to use 'Matlab' to illustrate how typical communication systems, both analogue and digital, can be simulated and analysed. Saeed [6] discussed the design module and describe a pedagogical approach that was adopted to teach a database management systems (DBMS) course. Mahmood [7] highlighted the weaknesses of the traditional methods of teaching and outlines an Objects-First approach for teaching a first course in software engineering. Almuhaideb [8] presented detailed guidelines to foster an effective outcome-based program framework based on the ABET accreditation experience of three different academic programs. Gull [9] analysed the relationship between the course of human computer interaction and other courses including psychology, sociology, anthropology, cultural studies, information science, computer science and design science. However, these research works are not specified for "digital communication" and the special characters are not concerned. For example, digital communication is highly related to hardware, which is not involved in the literature.

Therefore, it is of great importance to conduct research on the teaching and practice of digital communication. In order to meet the requirements of cultivating talents with solid theory and strong practical ability, we make propose to reform the course in terms of teaching content, training methods and evalatuion methods. Based on the experience in teaching prior theorical courses such as signal and system, communication principle, our new attemptes can guide students to practice training, and thus imporves their skills in dealing with practical problems, which will lay a solid foundation for becoming qualified professional and technical talents.

\section{Course reforming of digital communication}

Aiming at the problems in the teaching process of "digital communication", we propose to reform the course in terms of teaching content, training methods and assessment methods.

\subsection{Knowledge system based on information flow}

Table 1. Course system in digital communication systems

\begin{tabular}{|c|c|}
\hline Module & Prior Courses \\
\hline Source (ADC) & $\begin{array}{r}\text { analog electronic technology, digital electronic technology, signal } \\
\text { and system, digital signal processing }\end{array}$ \\
\hline Source Coding & $\begin{array}{r}\text { matrix theory, probability theory, information theory, digital } \\
\text { electronic technology }\end{array}$ \\
\hline Channel Coding & $\begin{array}{r}\text { matrix theory, probability theory, information theory, } \\
\text { communication theory, digital electronic technology }\end{array}$ \\
\hline Modulation/Demodulation & $\begin{array}{r}\text { analog electronic technology, digital electronic technology, signal } \\
\text { and system, digital signal processing }\end{array}$ \\
\hline Sink (DAC) & analog electronic technology, digital electronic technology \\
\hline
\end{tabular}

Based on the training program [10] and information flow in the digital communication system from the source to the sink, we re-organize the knowledge system of related courses 
as shown in Table 1. In this table, we established the relationship between the modules of digital communication and the prior courses, with which a knowledge system can be established reasonably to promote the teaching of "digital communication".

\subsection{Reformed teaching content}

Modern digital communication systems consist of complex modules including sampling, source coding, channel coding, transmission, multiplexing, frequency hopping, spread spectrum, synchronization, etc. It is impossible to cover such a complex system within limited teaching resources. However, many contents have been involved in prior courses such as signals and systems and communication principles. Therefore, it is necessary to reorganize the contents, and each course covers specified content and make them complementary. On the other hand, digital communication technology has achieved great development from $1 \mathrm{G}$ to $5 \mathrm{G}$ in the past two decades, and thus new technologies are being developed, and the course should also keep up with the new techniques, so that students can understand the latest technology in the industry. For example, Turbo code is widely used in $3 \mathrm{G}$, but is replaced in 5G by LDPC codes [11] and Polar codes [12]. To cope with this problem, we conducted investigation and studies on existing textbooks in aspects of theory, practice, practicability, operability and innovation. After that one main textbook and 2-3 reference textbooks can be determined. In addition, papers in international conferences and journals, as well as new technologies in the industry, can also be included. In this way, the in-depth study and arrangement of teaching content under the framework of digital communication system improves the teaching efficiency. In addition, it also promotes the interest and broaden the horizons of the students in learning new theories and knowledge.

\subsection{Online and offline teaching}

The last two years witnessed the booming development of online education, especially that the COVID-19 epidemic even promotes the online class to be much more popular. Generally speaking, online and offline teaching have their own advantages and disadvantages. In traditional offline teaching, teachers and students are in the same classroom and the face-to-face teaching is in high efficiency. Therefore, it is easier to use various teaching methods such as pictures and videos, and it also benefits the teachers for controlling the discipline. Nevertheless, offline teaching is restricted by time and the space, and needs great time and effort to analyse the statistical data about the class. In contrast, online courses have the flexibility of time and space. With the ability of video recording and playback, students can repeatedly watch the video and understand the difficult issues. At the same time, online teaching automatically performs efficient statistics of class data such as attendance and the answer of the homework. However, because teachers and students do not communicate face-to-face, the efficiency of teaching is low, and the behaviour of students could not be restrained.

Therefore, the integration of online and offline teaching methods can complement each other. On the one hand, we maintain traditional offline teaching to achieve efficient teaching and communication; on the other hand, we made full use of network resources and established an online course platform on the "Zhihuishu" platform to facilitate the learning at anytime and anywhere, and also achieved high efficiency course management. 


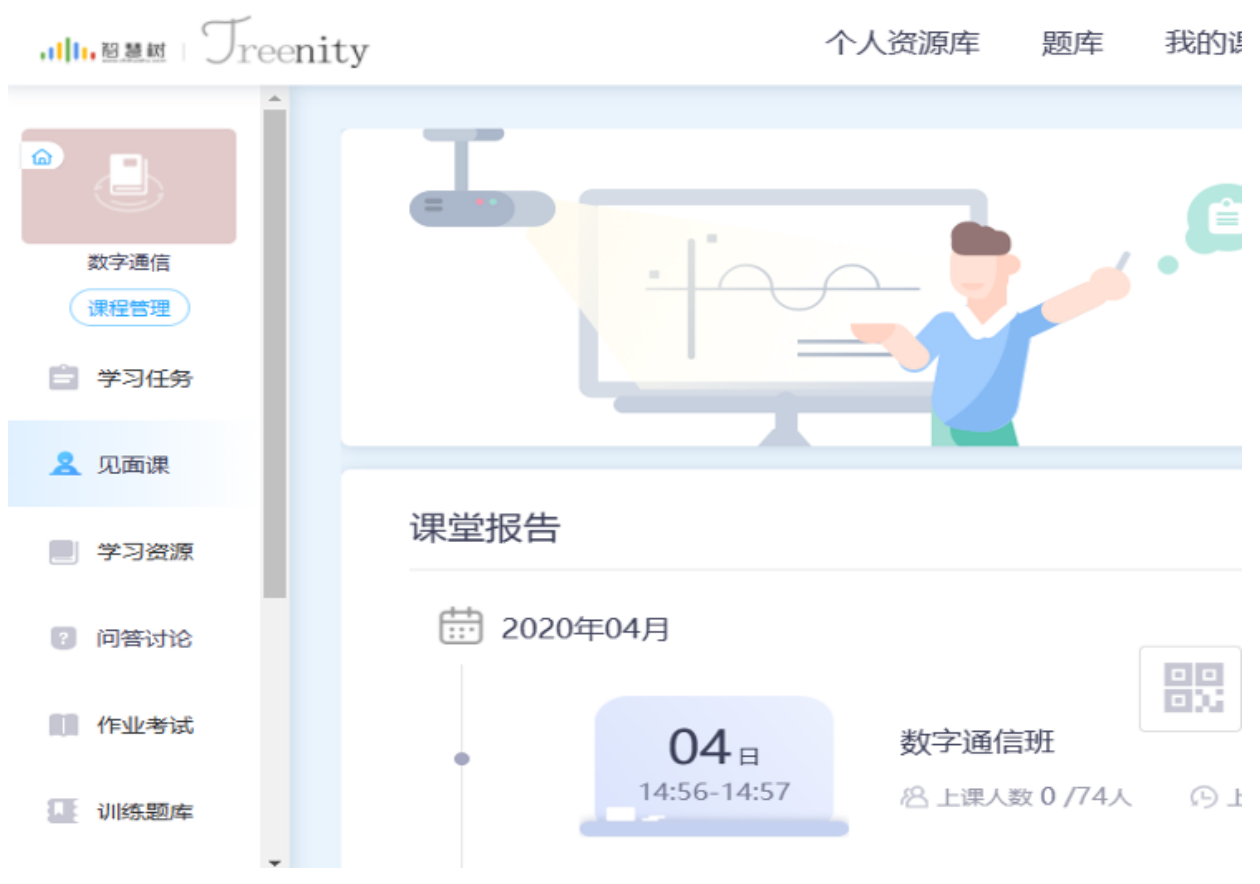

Fig. 1. The online class on the "Zhihuishu" platform.

\subsection{The combination of theory and practical communication system}

A major advantage of digital communication system is that it is quite common in all aspects of modern life, such as radio, TV, mobile phone, and satellite communication. Currently, the college students were born in the information age, and they are quite familiar with the emerging products. Therefore, it helps the students if the digital communication theory is combined with practical hardware device. For example, a cell phone motherboard with chips can be used when the modules of communication system are illustrated. The hardware device will make the class more interesting, and at the same time makes it easier to understand the theoretical knowledge.

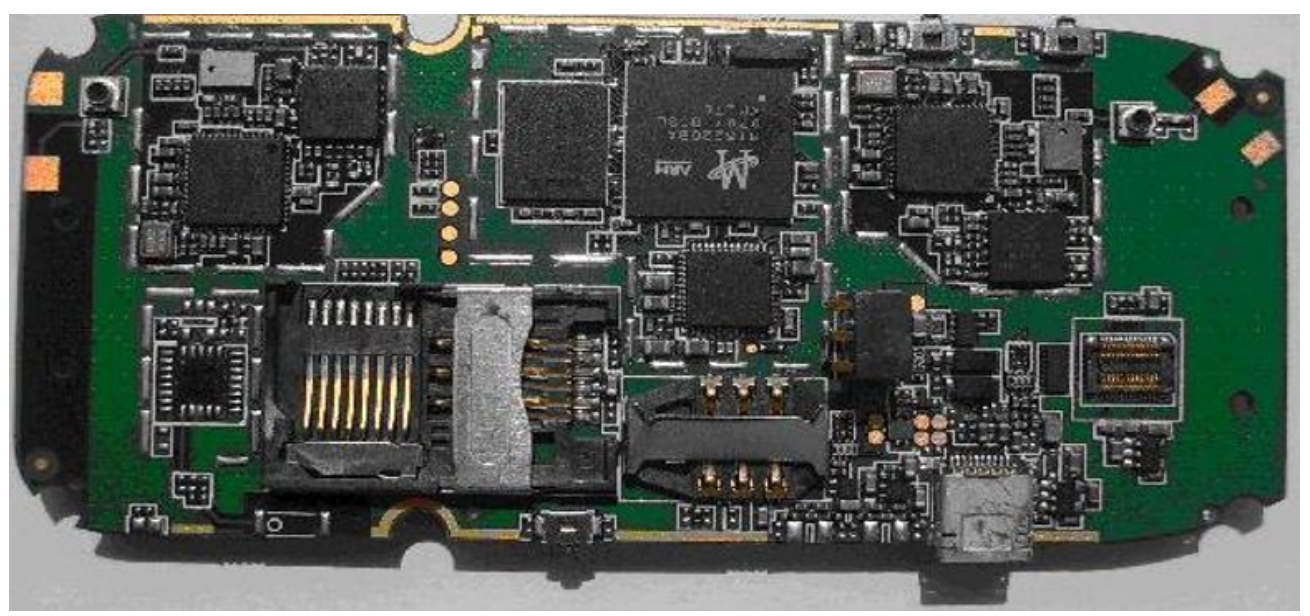

Fig. 2. An example of cellphone motherboard. 


\subsection{Experiments and practical training}

As a specialized course, the theory in digital communication is quite abstract. At the same time, if experiments and practical training are introduced, the results can be used to check the performance of the theory, and improves the teaching effect. Therefore, we make attempts on experiments and practical training.

On the one hand, experimental tasks are set to validate the important theoretical knowledge in the course. To be specific, teacher provide the topic and theoretical guidance, and the students will make the specific implementation of the experiment. On the other hand, the theories are integrated into various scientific and technological activities, such as "Challenge Cup", "Internet +" competition, "electronic design competition", "smart car competition" and other competitions. In these activities, students are encouraged to complete innovative tasks that related with digital communication. For example, in response to emerging issues such as $5 \mathrm{G}$, students are encouraged to conduct research on new technologies such as LDPC codes and Polar codes.

In addition, we also explored the cooperation between university and companies in terms of practical training. Taking the opportunities of cognitive internships and production internships, students go to KOTEI, Easystart(Yisida) and other companies, as well as the joint innovation base for 2025 industry and education. In the training process, the theoretical knowledge in the textbooks are better understand for the students.

\subsection{Comprehensive grading system}

Digital communication uses mathematics and signal processing theory to solve specific problems in communication systems. On the one hand, this course is theoretically complex and difficult. On the other hand, the course is highly related with specific problems of the communication system. Therefore, it is not reasonable to simply grade the students solely based on the examinations. Based on this, we proposed a comprehensive grading system that integrates in-class tests, homework, experimental practice, and examinations. Firstly, right after the theories, such as linear block codes and cyclic codes, are described in class, exercises and tests can consolidate the knowledge points. Secondly, after-school homework is arranged based on the examples in the textbook, which are used to consolidate the fundamental and difficult knowledge points that require in-depth study. Thirdly, experimental practice promotes the students' ability to use theory in practical software and hardware development. Finally, the exam is a comprehensive test and evaluation in limited time. The overall grades of the students are given by comprehensively considering the aspects above. This grading system enhances the diversity and interest of teaching, enhances students' interest, and achieves better teaching effects.

\section{Results}

The proposals are conducted on undergraduate students majoring in "communication engineering" in Wuhan University of Science and Technology from 2017 to 2021. Each year, about 75 students are involved in the teaching and cultivating reforming. After four years' attempt, quite good results are obtained in the course reforming.

On the one hand, the evaluation grades of are greatly improved. About $38 \%$ percent of students get the grade "Excellent", where the overall score exceeds 90, and 29\% get "good" with the score between 80 and 90 . On the other hand, many students win prizes in various competitions including "National Undergraduate Electronic Design Competition", "National College Student Robotics Competition", "University Student Information Technology Innovation Competition in Hubei Province" and many other competitions. 
The results prove that, with our course reformation proposals, the students not only better understand the principles, but also with quite good practical abilities

\section{Conclusions}

In this paper, we explored the teaching of digital communication courses. Considering the fact that the course is theoretically difficult, highly related to prior courses, as well as the close connection with the actual communication systems, we have explored the knowledge system, teaching content, teaching methods, and assessment methods. We first sorted out the relevant courses according to the processing flow of the information in the digital communication system, and established a knowledge system. After that, the course content is determined by joint considering the prior course and the emerging techniques in communication industry. Thirdly, in terms of teaching methods, we propose to combine online and offline teaching, combine theory and physical system, and combine experimental and practical training. Finally, in terms of student performance grading, a comprehensive evaluation system that combines in-class tests, homework, experiments, and examinations is proposed. The above research will benefit the teaching and learning of digital communication in quality, efficiency and also more in-depth, and will also cultivate high-quality compound new engineering talents with both theoretical and practical abilities.

This work was supported by the Teaching and Research Projects of Wuhan University of Science and Technology (2018X056) and Provincial Teaching and Research Projects in Hubei Universities (No. 2020356).

\section{References}

1. M. Shafi, A. Molisch, P. Smith, et al., 5G: A tutorial overview of standards, trials, challenges, deployment, and practice, IEEE journal on selected areas in communications, 35(6): 1201-1221(2017)

2. Notice About the Construction, Development of New Engineering, Implementation of Excellence by Ministry of Education, Ministry of Industry and Information Technology, Chinese Academy of Engineering, [online] Available: http://www.moe.gov.cn/srcsite/A08/moe_742/s3860/201810/t20181017_351890.html

3. D. Silage, Teaching digital communications in a wireless world: Who needs equations?, in Proceedings of the 2006 Annual Conference \& Exposition, 18-21 June 2006, Chicago, USA (2006)

4. Z. Mahmood, S. Saeed, Teaching Quality Assurance and Project Management to Undergraduate Computing Students In Pakistan, in Proceedings of the 4th International Conference on Business, Management and Economics, 5-7 June 2008, Cesme, Turkey (2008)

5. Z. Ghassemlooy, R. Saatchi, Software simulation techniques for teaching communication systems, International journal of electrical engineering education, 36(4), 287-297(1999).

6. S. Saeed, R. Aamir, Z. Mahmood, Reflections on teaching database management systems to undergraduate students, International Journal of Education Economics and Development, 2(4), 398-411(2011)

7. Z. Mahmood, Teaching software engineering to undergraduate computing students, International Journal of Teaching and Case Studies, 3(2-4), 112-122(2011). 
8. A. M. Almuhaideb, S. Saeed, Fostering sustainable quality assurance practices in outcome-based education: lessons learned from ABET accreditation process of computing programs. Sustainability, 12(20), 8380(2020).

9. H. Gull, S. Saeed, S. Iqbal, et al., Reflections on teaching human computer interaction course to undergraduate students, in Proceedings of International Conference on Computational Science and Computational Intelligence (CSCI). IEEE, 12-14 Dec 2018, Las Vegas, USA (2018)

10. Training Program of Electronic information, [online] Available: http://www.wust.edu.cn/xxkx/2018/0813/c644a158620/page.htm

11. Y. Zhang, K. W. Peng, X. Wang, et al., Performance analysis and code optimization of IDMA with 5G new radio LDPC code, IEEE Communications Letters, 22(8): 15521555 (2018)

12. V. Bioglio, C. Condo, I. Land, Design of polar codes in $5 \mathrm{G}$ new radio, IEEE Communications Surveys \& Tutorials, 23(1): 29-40 (2020) 